\title{
Scoliosis and sagittal balance in Parkinson's disease: analysis of correlations
}

\author{
Luciano Bissolotti, Massimiliano Gobbo, Fabio Zaina, Monia Lusini, Sabina Donzelli, Stefano Negrini \\ From 10th International Conference on Conservative Management of Spinal Deformities - SOSORT 2013 \\ Annual Meeting \\ Chicago, IL, USA. 8-11 May 2013
}

\section{Background}

Information concerning scoliosis in Parkinson's disease (PD) and its correlations with sagittal balance (SB) is sparse.

\section{Purpose}

The aim of this study was to describe the prevalence of scoliosis in PD patients and the existing correlations with $\mathrm{SB}$ in relation to the spinopelvic morphology.

\section{Methods}

A total of 48 consecutive PD patients were included: 36 males, 12 females; $70.8 \pm 7.6$ years; $6.4 \pm 4.1$ years of disease (YOD); Hoehn Yahr (HY) 2.7 \pm 1.2 . The clinical assessment included HY score, Pain NRS 0-10 and trunk rotation in bending (ATR). Lumbar lordosis (LL), thoracic kyphosis (TK), scoliosis curves (SC), spinosacral angle (SSA), spinopelvic angle (SPA), pelvic incidence (PI), sacral slope (SS) and pelvic tilt (PT) were radiographically assessed. Patients have been compared according to the presence of $\mathrm{SC}>10^{\circ}\left(\mathrm{PD}_{\mathrm{ts}}\right)$ Cobb or the absence of $\mathrm{SC}\left(\mathrm{PD}_{\mathrm{ns}}\right)$.

\section{Results}

Among the study subjects, $47.9 \%$ presented a SC larger than $10^{\circ}, 84 \%$ of the patients in $\mathrm{PD}_{\mathrm{ts}}$ presented a thoracolumbar curve, $10 \%$ a thoracic curve and $6 \%$ a lumbar curve. The cohort did not present differences with $\mathrm{PD}_{\mathrm{ns}}$ about age (71.8 \pm 6.0 vs. $69.8 \pm 8.8 \mathrm{yrs})$ and YOD $(6.1 \pm 4.1$ vs. $6.6 \pm 4.1$ years). No differences have been detected for HY score $(2.7 \pm 1.2$ vs. $2.6 \pm 1.6)$ and NRS (29.6 \pm 22.6 vs. $19.4 \pm 28.1)$. ATR was higher in $\mathrm{PD}_{\mathrm{ts}}(5.6 \pm 4.9$ vs. $1.3 \pm 1.9$, $\mathrm{p}<0.01)$. TK $\left(46.4 \pm 16.1\right.$ vs. $\left.46.9 \pm 12.1^{\circ}\right)$, LL $(46.3 \pm 26.9$ vs. $\left.49.3 \pm 13.9^{\circ}\right)$, SSA $\left(104.8 \pm 24.7\right.$ vs. $\left.118.6 \pm 12.9^{\circ}\right)$ and SPA $\left(152.4 \pm 20.3\right.$ vs. $\left.153.4 \pm 12.5^{\circ}\right)$ were not different ( $\left.>0.05\right)$. PI $\left(57.8 \pm 11.1\right.$ vs. $\left.53.9 \pm 13.1^{\circ}\right)$ and PT $(23.6 \pm 13.7$ vs. $\left.17.6 \pm 8.6^{\circ}\right)$ were slightly but not statistically different, while SS was not $\left(35.3 \pm 12.1\right.$ vs. $\left.36.0 \pm 8.5^{\circ}\right)$.

\section{Conclusions and discussion}

The prevalence of scoliosis in PD was higher than previously described by other authors, with the thoracolumbar spine mostly affected. SB was not different between two groups while, in $\mathrm{PD}_{\mathrm{ts}}$, spinopelvic parameters presented the tendency to have a larger PI and PT.

Published: 18 September 2013

\section{References}

1. Koller H, Acosta F, Zenner J, Ferraris L, Hitzl W, Meier O, Ondra S, Koski T, Schmidt R: Spinal surgery in patients with Parkinson's disease: experiences with the challenges posed by sagittal imbalance and the Parkinson's spine. Spine J 2010, 19(10):1785-94, Epub 2010 Apr 27.

2. Doherty KM, van de Warrenburg BP, Peralta MC, Silveira-Moriyama $\mathrm{L}_{\text {, }}$ Azulay JP, Gershanik OS, Bloem BR: Postural deformities in Parkinson's disease. Lancet Neurol 2011, 10(6):538-549.

3. Baik JS, Kim JY, Park JH, Han SW, Park JH, Lee MS: Scoliosis in patients with Parkinson's disease. J Clin Neurol 2009, 5(2):91-94.

doi:10.1186/1748-7161-8-S2-O7

Cite this article as: Bissolotti et al:: Scoliosis and sagittal balance in

Parkinson's disease: analysis of correlations. Scoliosis 2013 8(Suppl 2):07.

* Correspondence: Luciano.bissolotti@ancelle.it

Rehabilitation Service, Casa di Cura Domus Salutis, Brescia, Italy

(c) 2013 Bissolotti et al.; licensee BioMed Central Ltd. This is an Open Access article distributed under the terms of the Creative 